\title{
SEISMIC VULNERABILITY ASSESSMENT OF SKEWED REINFORCED CONCRETE BRIDGES
}

\author{
A. Ghanem ${ }^{(1)}$, D. Moon ${ }^{(2)}$, Y. Lee ${ }^{(3)}$, \\ (1) Ph.D. Student, University of Hawai 'i at Mānoa, aghanem@hawaii.edu \\ (2) Assistant Professor, University of Hawai 'i at Mānoa,dsmoon@hawaii.edu \\ (3) Assistant Professor, Ulsan National Institute of Science and Technology (UNIST), ylee@ unist.ac.kr
}

\begin{abstract}
Skewed bridges are commonly used in highway interchanges where the straight (unskewed) bridges are not suitable. There have been several observations of heavy damage of bridges that have geometric irregularities, especially significant skewness. Such damage severely disrupts transportation systems, leading to substantial economic consequences. Skewed bridges are often inevitable due to the complexity and lack of orthogonality of transportation networks; hence better quantification of the effects of skewness on the bridge performance is a more viable approach than avoiding skewed bridges. This research focuses on the seismic vulnerability analysis of skewed reinforced concrete (RC) bridges. From the straight to highly skewed, various bridge models are created based on design example No. 4 prepared by the US Federal Highway Administration (FHWA). A set of earthquake ground motion records is carefully selected to impose consistent seismic demands on bridges. The fragility relationships for all bridge configurations are derived from the non-linear dynamic response history analysis. A new structural reliability method is utilized to handle the computational challenge in deriving fragility curves, which incorporates the structural analysis and reliability analysis to calculate the failure probability efficiently and accurately with the first-order reliability method (FORM). An attempt is made to parameterize the problem based on the skew angle. It is shown that the skew angle has a direct effect on the seismic vulnerability of RC bridges. The results reported will be helpful for new designs of skew RC bridges.
\end{abstract}

Keywords: seismic vulnerability; skewed bridge; fragility curve; first-order reliability method 


\section{Introduction}

Reinforced concrete highway bridges are common structures in any transportation system where their unique seismic responses are complicated due to their complexity and irregular geometries (e.g., skewed alignment). The operation of the transportation systems will be disrupted by the failure of the bridges due to earthquakes, which is a significant loss of victims and economic problems. Therefore, the safety and the performance of bridges under extreme loading conditions are of prime importance to structural researchers. Due to significant damages to the skewed bridges that were repeatedly observed during many past earthquakes worldwide [1-4], many researchers evaluated the seismic vulnerability of various skewed reinforced concrete bridges to predict the damage of the bridges in advance [5].

In this regard, to represent the probability of failure of bridges caused by earthquake hazards, seismic fragility curves or seismic vulnerability curves have been used [6]. This failure probability is predefined by damage state criteria for different levels of ground motion intensity [7]; it shows the performance of the bridges during earthquake events as a graphical representation of seismic risk. Deriving appropriate and accurate fragility curves is one of the most critical tasks in seismic vulnerability assessment of structures because they significantly affect the overall assessment outcomes.

Several research efforts have investigated the effects of skew angle on the seismic response of bridges. Recent studies have shown that some irregular bridges, such as skew bridges, have the potential for significant damage compared to straight bridges under earthquake events [8-9] and that the boundary conditions have a considerable effect on the bridge response. [10]. The shear and compressive capacities of the bridge piers are also reduced significantly in irregular bridges [11-12]. In many cases, previous studies have used simplified models, which may be insufficient to evaluate the seismic vulnerability of bridges having a high degree of skewness. It could not accurately evaluate highly non-linear structural behavior due to the torsional moment effect on the columns.

In this study, three-dimensional representations are used to evaluate the accurate seismic performance of various bridge models, from the straight to highly skewed, are created based on design example No. 4 prepared by the US Federal Highway Administration (FHWA) [13]. A set of earthquake ground motion records is carefully selected to impose consistent seismic demands on bridges. However, using a three-dimensional model in fragility analysis is challenging as it increases the computational time and cost. A new structural reliability method is utilized to overcome this challenge, which incorporates the structural analysis and reliability analysis to calculate the failure probability efficiently and accurately with the first-order reliability method (FORM) [14]. 


\section{Fragility Curve Evaluation}

The seismic fragility curve can be defined as a relation between the earthquake peak ground acceleration (PGA) and the probability of failure of structures when reaching or exceeding the specifically defined damage state criteria [15]. There are different methods to develop the seismic fragility curve. The existing techniques can be divided into two main groups depending on whether an analytical-based function or a simulation-based is used [16].

In the analytical-based method, the failure probability is calculated based on the likelihood of reaching a predefined limit state condition, where this limit state can be calculated as a difference between the structural capacity and the seismic response. This method depends on developing a closed-formed expression by representing the structural capacity and the seismic response as an analytical function of related parameters such as the peak ground acceleration and the natural period of the structures. The analytical-based method is commonly allowed to be used for a static analysis rather than dynamic time history analysis due to the assumptions of this approach [17].

In the simulation-based method, it is required to generate several random variables to perform structural analysis and count the number of the failure cases where the corresponding structure response was reaching or exceeding the certain defined damage state criteria [18]. The simulationbased method, such as Monte Carlo simulation (MCS), can perform inelastic pushover or dynamic time history analysis. However, this method requires a large sample to get high accuracy outcome, so it is time-consuming when it is necessary to get a relatively low failure probability.

This paper provides another methodology to drive the fragility analysis. This method lies between the analytical-based and the simulation-based methods, which require coupling of both reliability and structural analysis to get the limit state function and the probability of failure. The limit state surface is usually approximated at the design point as a tangent plane called the first-order reliability method (FORM) or parabola, called the second-order reliability method (SORM). To decrease the computational time consumed in the analysis, FORM is used in the adopted method. FORM is an effective tool to obtain the failure probability.

The failure limit state is defined by a function of $\mathbf{x}$ in the original space, where $\mathbf{x}$ is a random variable vector. Then using matrix transformation, the random variables are converted to the corresponding standard normal space, and the limit-state function is redefined by a function of $\mathbf{u}$, where $\mathbf{u}$ is the column vector of log-normal variables [19]. After that, by approximating the limit state function using the first-order Taylor series and calculating the reliability index $(\beta)$ as a minimum 
distance from the original to the approximate limit state function in the standard normal space, the probability of failure can be calculated as

$$
P_{f}=\Phi(-\beta)
$$

Where $\Phi=$ cumulative distribution function of the log-normal distribution. Figure 1 shows the linearized limit-state function for the failure domain in the two-dimensional standard normal space and the minimum distance from the origin to the approximated linear function [20].

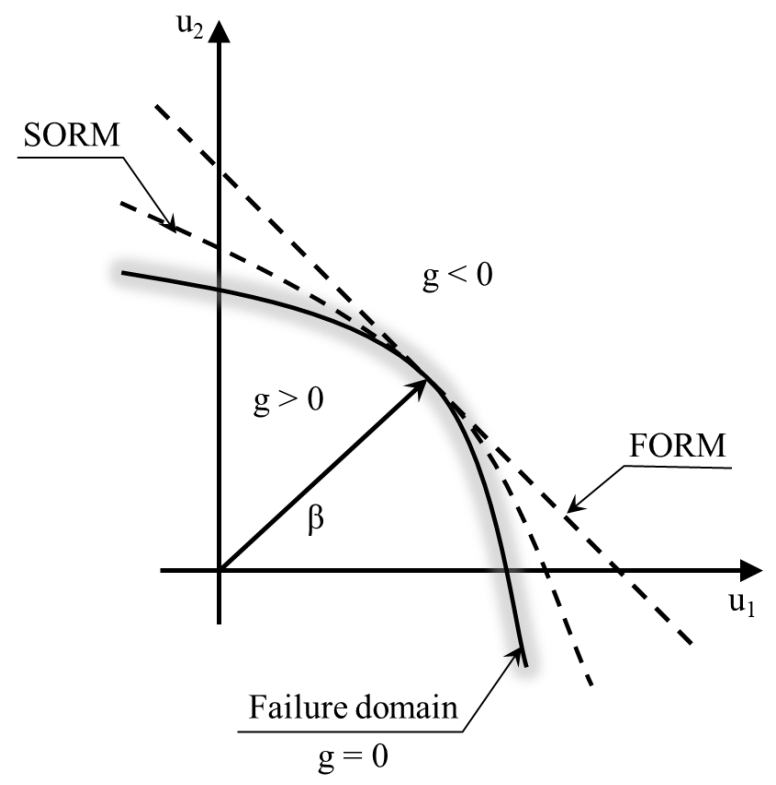

Figure 1 - Linear approximation in FORM [21]

\section{Integrated Framework}

The methodology used in this paper requires the coupling of reliability analysis and structural analysis. The reliability analysis package, the Finite Element Reliability Using MATLAB (FERUM), was developed by researchers at the University of California at Berkeley [22]. FERUM offers many functions such as FORM, SORM, and MCS, which have been widely used in various engineering applications.

For the structural analysis, ZEUS-NL is used, which is a fiber element non-linear analysis program provided by the Mid-America Earthquake (MAE) Center [23]. It is an advanced structural analysis software that was specially developed for earthquake engineering applications. ZEUS-NL is generally used for different non-linear static and dynamic analyses [24]. It uses fiber-based element modeling, which considers the material inelasticity within the element cross-section and the element length. 
The integrated platform FERUM-ZEUS was developed as a platform in MATLAB to link and exchange the analysis data between FERUM and ZEUS-NL to accurately calculate the probability of failure and create the fragility curves. Figure 2 presents a graphical representation of the FERUMZEUS platform. FERUM determines a specific value for the random input variables and sends it to ZEUS-NL. Then, ZEUS-NL creates the analytical model to determine the structure capacity (supply) from the pushover analysis and the seismic response (demand) from the inelastic time history analysis. The analysis outcomes are sent back to FERUM to repeatedly calculate the limit-state function as supply minus demand until the failure probability is found by FORM.

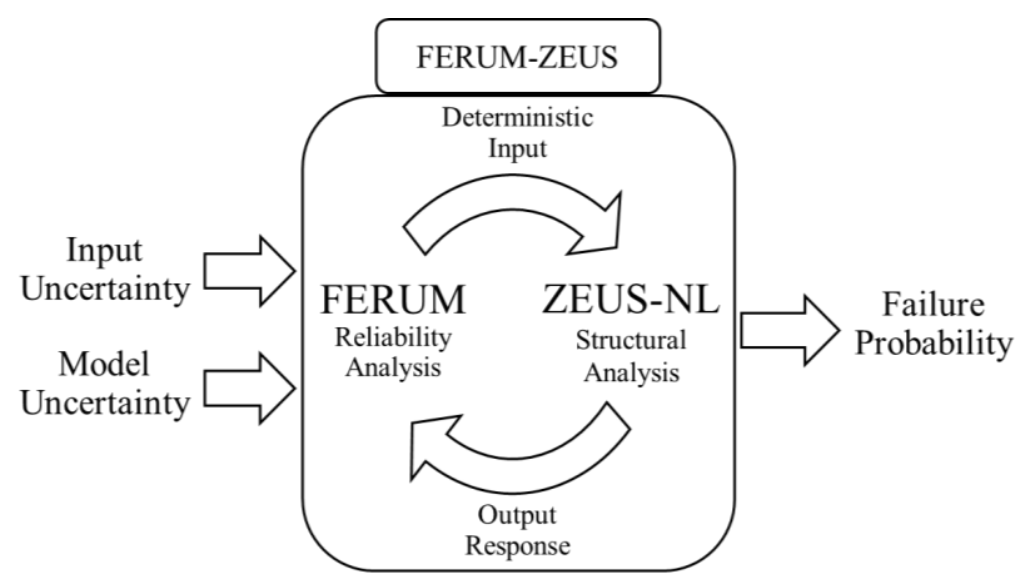

Figure 2 - The integrated platform of FERUM-ZEUS

The use of more computationally demanding models becomes practically feasible with the help of the computational platform FERUM-ZEUS. Fragility curves of three-dimensional structures can be obtained on a standard personal computer (Intel(R) Core(TM) i7-9700K, $3.60 \mathrm{GHz}$ CPU, 16 Gb RAM). If the same numerical problem is solved with the most widely used Monte Carlo simulation, obtaining fragility curves would be extremely time-consuming, as the computational cost of each structural analysis becomes much expensive with the use of the three-dimensional models.

Furthermore, to reduce the computational cost of the studied models, parallel computing techniques using MATLAB were implemented by controlling and maximizing the usage of the local multicore processors to reduce the computational time it takes to reach an appropriate and accurate seismic performance. 


\section{Seismic Vulnerability Analysis}

\subsection{Analytical Models}

Three-dimensional reinforced concrete bridges with different skew angles were evaluated. These models were developed based on design example No. 4 prepared by the US Federal Highway Administration (FHWA). The concrete bridge consists of three spans of $30.48 \mathrm{~m}, 36.58 \mathrm{~m}, 30.48 \mathrm{~m}$ for a total bridge length of $97.54 \mathrm{~m}$. Six analytical models were developed with $0,15,30,45,60,75$ degree skewed angles perpendicular to a straight bridge centerline alignment.

The superstructure is made of a cast-in-place reinforced concrete box girder with two interior webs. The intermediate bents have a cross beam integral with the box girder and two round columns on top of spread footing foundations. The seat-type abutments are spread footings, and the intermediate bents are all cast-in-place concrete [13]. The plan and elevation of the bridge are shown in Figure 3.

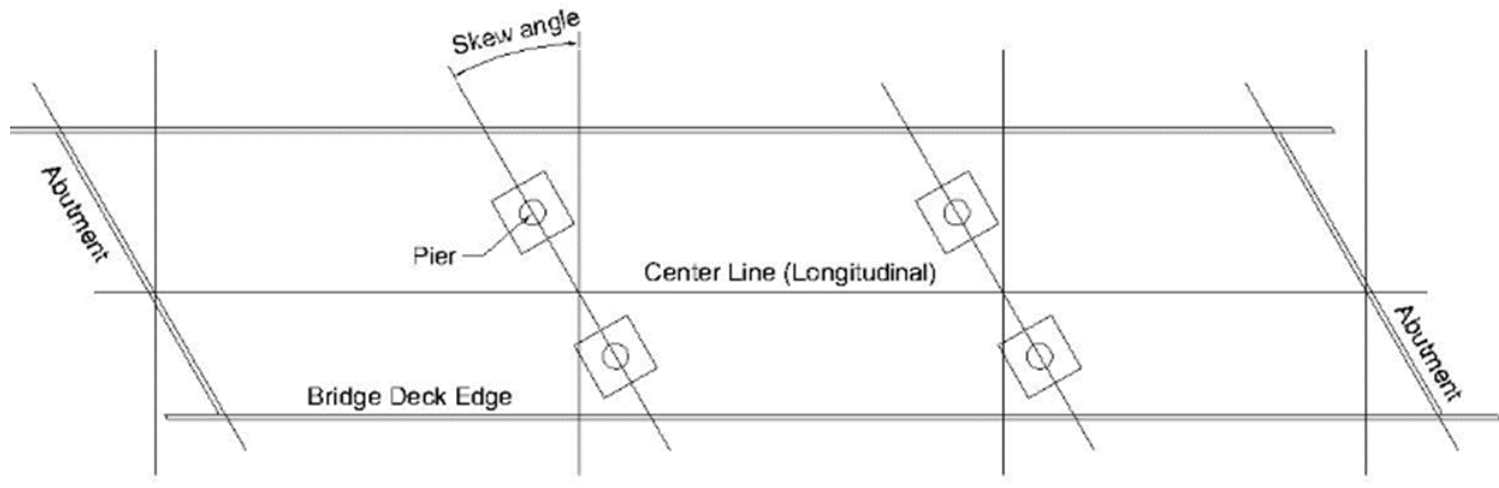

PLAN

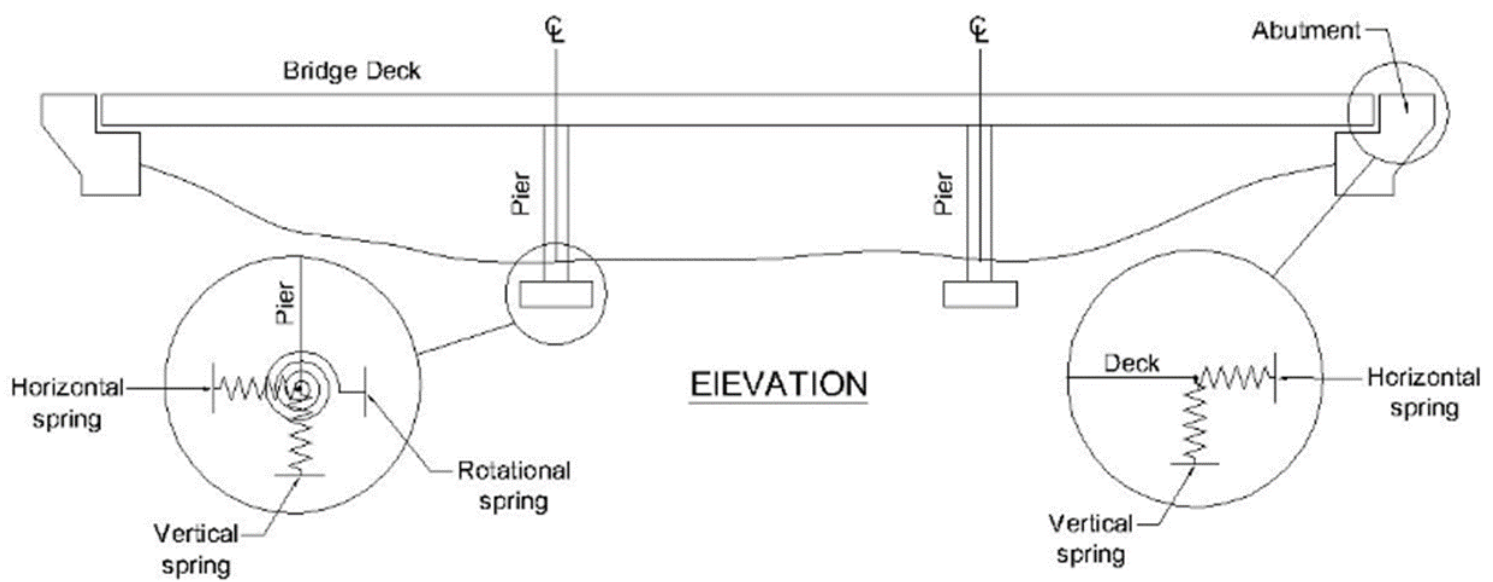

Figure 3 - Plan and elevation of the design example No. 4 bridge 
The analytical model was developed in the non-linear finite element analysis program ZEUSNL. Each girder and column was divided into six and seven elements, respectively. The reinforced concrete beams had a hollow rectangular section with $1030.9 \mathrm{~cm}$ external width, $909.2 \mathrm{~cm}$ internal width, and $182.9 \mathrm{~cm}$ external depth, $133.1 \mathrm{~cm}$ internal depth. The reinforced concrete columns had a circular section with a $121.9 \mathrm{~cm}$ diameter. Figure 4 shows a three-dimensional numerical model created in ZEUS-NL.

Also, the material nonlinearity was considered in the modeling based on a bilinear elastoplastic model with kinematic hardening and modified Mander's model [25] are employed for steel and concrete, respectively.

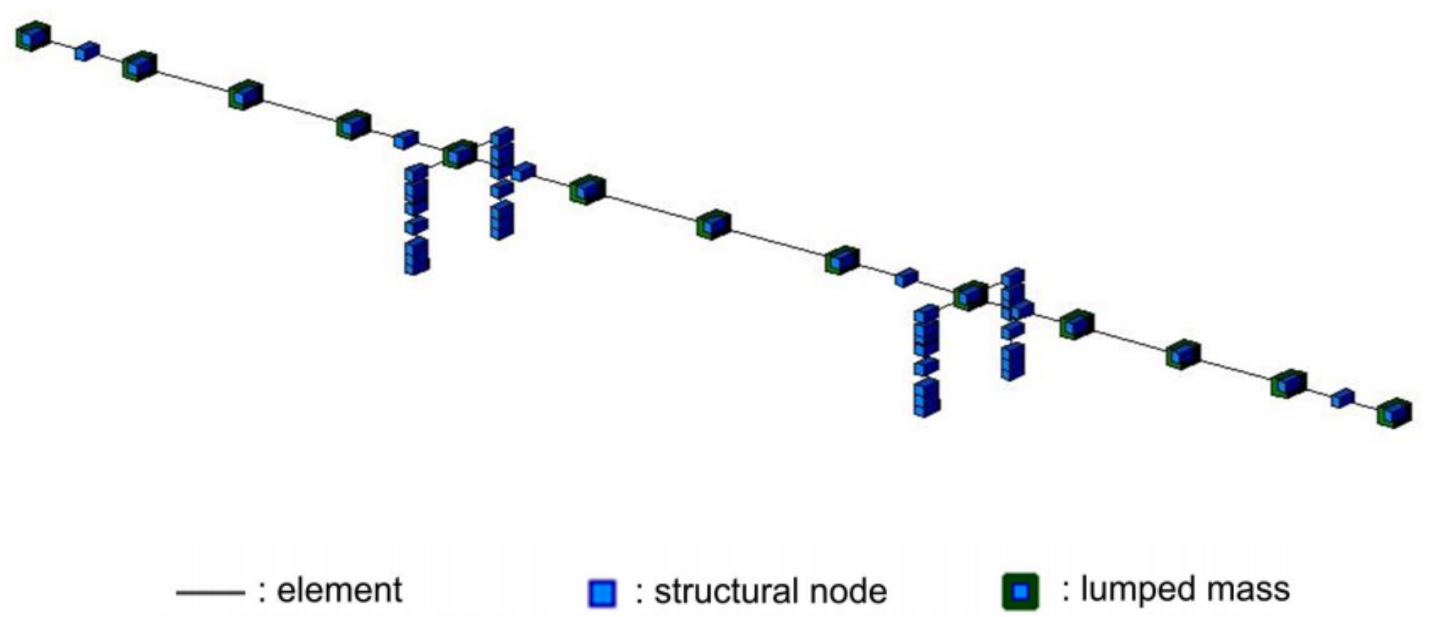

Figure 4 - Three-dimensional numerical model.

Six different types of analytical models were developed; one of them is for a regular unskewed model (SK000), and five are for irregular skewed models (SK015, SK030, SK045, SK060, and SK075) with 15, 30, 45, 60, and 75-degree skewed angle perpendicular to a straight bridge centerline alignment, respectively.

Table 1 summarizes the skewness angles, fundamental periods, and reference names of the six analytical models. The first period (fundamental period) decreases as the skewness angle increases due to the rise of the lateral stiffness of the system with the increase of the skewness angle. Figure 5 shows the first three mode shapes of the regular model and 75-degree skewed angle irregular mode. The first and second modes correspond to the translational response in the longitudinal and transverse direction, and the third mode corresponds to the torsional response. 
Table 1 - Fundamental periods of analytical models

\begin{tabular}{|l|c|c|c|c|c|c|}
\hline \multirow{2}{*}{\multicolumn{1}{c}{ Model property }} & Regular & \multicolumn{5}{c|}{ Irregular } \\
\cline { 2 - 7 } & SK000 & SK015 & SK030 & SK045 & SK060 & SK075 \\
\hline Skewness angles (degree) & 0 & 15 & 30 & 45 & 60 & 75 \\
\hline First period (s) & 0.6687 & 0.6678 & 0.6644 & 0.6568 & 0.6424 & 0.6199 \\
\hline Second period (s) & 0.2905 & 0.2827 & 0.2637 & 0.2615 & 0.3183 & 0.3846 \\
\hline Third period (s) & 0.2142 & 0.2171 & 0.2291 & 0.2412 & 0.2204 & 0.2028 \\
\hline
\end{tabular}

$1^{\text {st }}$ mode: $0.6687 \mathrm{sec}$

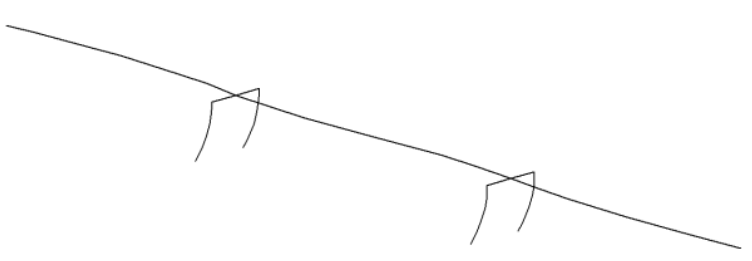

$2^{\text {nd }}$ mode: $0.2905 \mathrm{sec}$

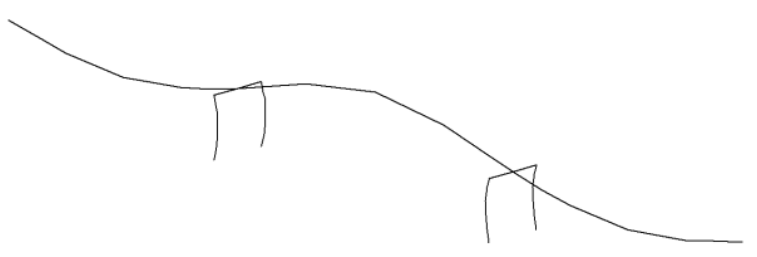

$3^{\text {rd }}$ mode: $0.2142 \mathrm{sec}$

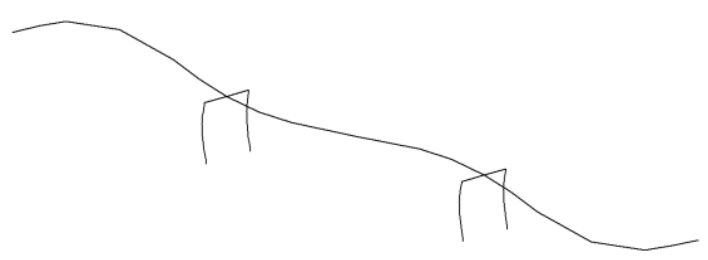

(a) $1^{\text {st }}$ mode: $0.6199 \mathrm{sec}$

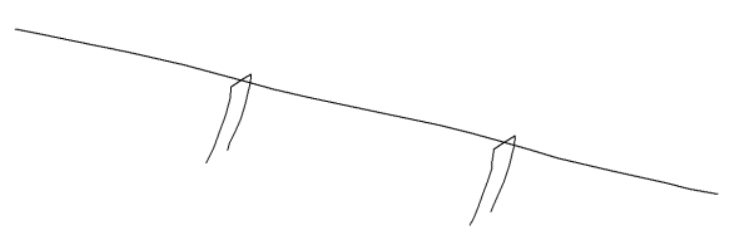

$2^{\text {nd }}$ mode: $0.3846 \mathrm{sec}$

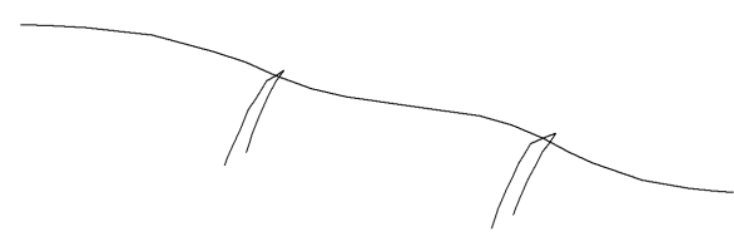

$3^{\text {rd }}$ mode: $0.2028 \mathrm{sec}$

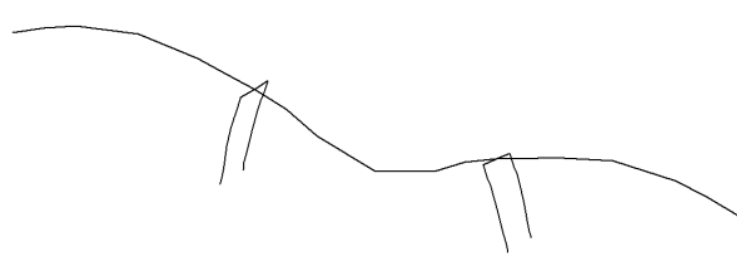

(b)

Figure 5 - First three mode shapes of selected analytical models: (a) regular model (SK000), and (b) 75-degree skewed angle irregular model (SK075). 


\subsection{Input Ground Motions}

A total of 15 records were chosen from the Pacific Earthquake Engineering Research Center (PEER) ground motion database to account for many seismo-tectonic features and seismic site effects to consider the possible seismic demands on structures from different earthquake events [26].

In this approach, the selected ground motion records were scaled from $0.02 \mathrm{~g}$ with an increment of $0.02 \mathrm{~g}$ till $1.00 \mathrm{~g}$ to consider equal velocity spectrum intensity in the period range of the bridges. The acceleration time-history records of the selected ground motions are presented in Figure 6, and Selected ground motion response spectra are shown in Figure 7. Details on selected ground motions are provided in Table 2.

Table 2 - Properties of selected ground motions

\begin{tabular}{|c|c|c|c|c|}
\hline Earthquake & Year & Magnitude & PGA (g) & Reference number \\
\hline Bucharest & 1977 & 6.4 & 0.19 & 01 \\
\hline Erzincan & 1992 & 5.5 & 0.39 & 02 \\
\hline Montenegro & 1979 & 6.2 & 0.12 & 03 \\
\hline Kalamata & 1986 & 5.5 & 0.22 & 04 \\
\hline Kocaeli & 1999 & 7.6 & 0.31 & 05 \\
\hline Friuli & 1976 & 6.1 & 0.08 & 06 \\
\hline Athens & 1999 & 5.3 & 0.11 & 07 \\
\hline Umbro-Marchigiano & 1997 & 5.8 & 0.10 & 08 \\
\hline Lazio Abruzzo & 1984 & 5.7 & 0.06 & 09 \\
\hline Basso Tirreno & 1978 & 5.6 & 0.07 & 10 \\
\hline Gulf of Corinth & 1993 & 4.7 & 0.07 & 11 \\
\hline Montenegro & 1979 & 6.2 & 0.07 & 12 \\
\hline Montenegro & 1979 & 6.2 & 0.17 & 13 \\
\hline Friuli & 1976 & 6.3 & 0.36 & 14 \\
\hline Umbro-Marchigiana & 1997 & 5.0 & 0.04 & 15 \\
\hline
\end{tabular}



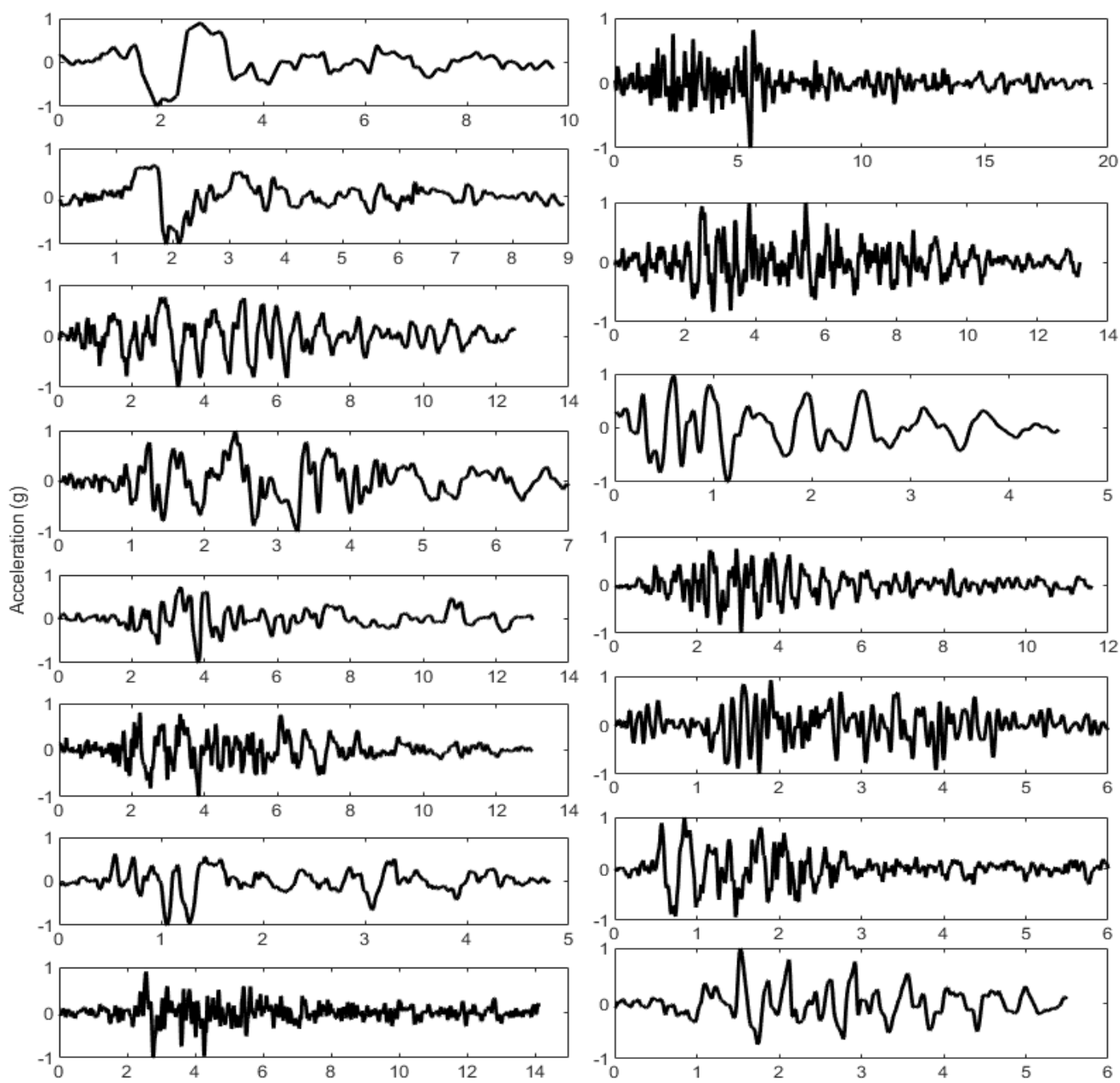

Time (Sec.)

Figure 6 - Selected ground motion records

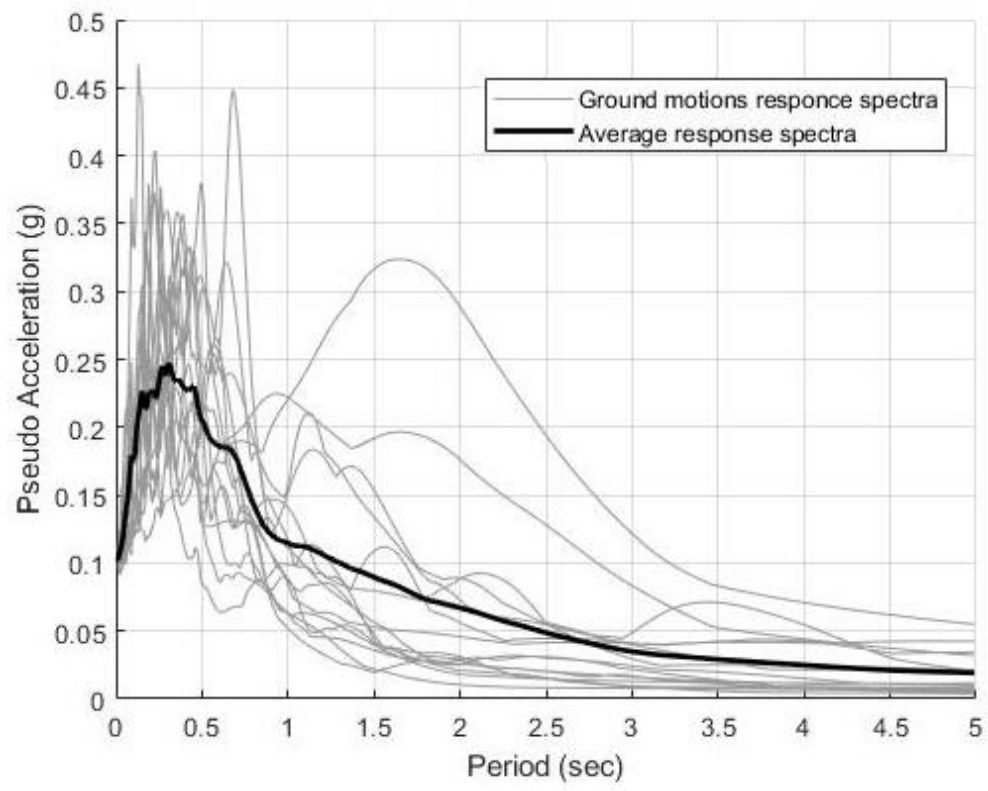

Figure 7 - Selected ground motion response spectra 


\subsection{Definition of Uncertainty and Limit State}

The uncertainty in the structural capacity (supply) and the earthquake hazard (demand) was considered in deriving the fragility curves of three-dimensional reinforced concrete bridges. The uncertainty in earthquake loads, or demand, is taken into account by using various ground motion records in the analysis.

Uncertainty in structural capacity, or supply, is considered by considering the concrete ultimate strength and the steel yield strength as random variables. The concrete ultimate strength was 40.9 $\mathrm{MPa}$, and the in-place strength of concrete is assumed to have a log-normal distribution of a mean of 33.6 MPa and a coefficient of variance of $18.6 \%$ [27].

The reinforcement is designed with grade 40 steel, and the yield strength of reinforcing steel is assumed to follow a log-normally distributed with a mean of $427.5 \mathrm{MPa}$ and a coefficient of variance of $10.7 \%$ [28]. A summary of the statistical properties of the random variables considered in the study. As shown in Table 3.

Table 3 - Statistical properties of random variables

\begin{tabular}{|c|c|c|c|}
\hline Random variable & Distribution type & Mean (MPa) & Coefficient of variation \\
\hline Concrete ultimate strength & log-Normal & 40.9 & 0.186 \\
\hline Steel yield strength & log-Normal & 427.5 & 0.107 \\
\hline
\end{tabular}

This study employs three levels of limit state: serviceability, damage control, and collapse prevention. The serviceability limit state is defined at the first yielding of reinforcing steel in column members. The damage control and collapse prevention states are determined at the maximum element strength and maximum confined concrete strain in column members, respectively [29].

The Column drift (CLD) is utilized to determine if a structure is failed based on the limit-state definition. To determine threshold values of CLDs corresponding to each limit-state condition, a series of pushover analyses are conducted with six different prototype bridge models. Figure 8 compares total base shear force versus maximum column drift ratio from the pushover analysis using the inverted triangle (code defined), and it graphically shows that structures with more irregularity have less seismic capacity. 


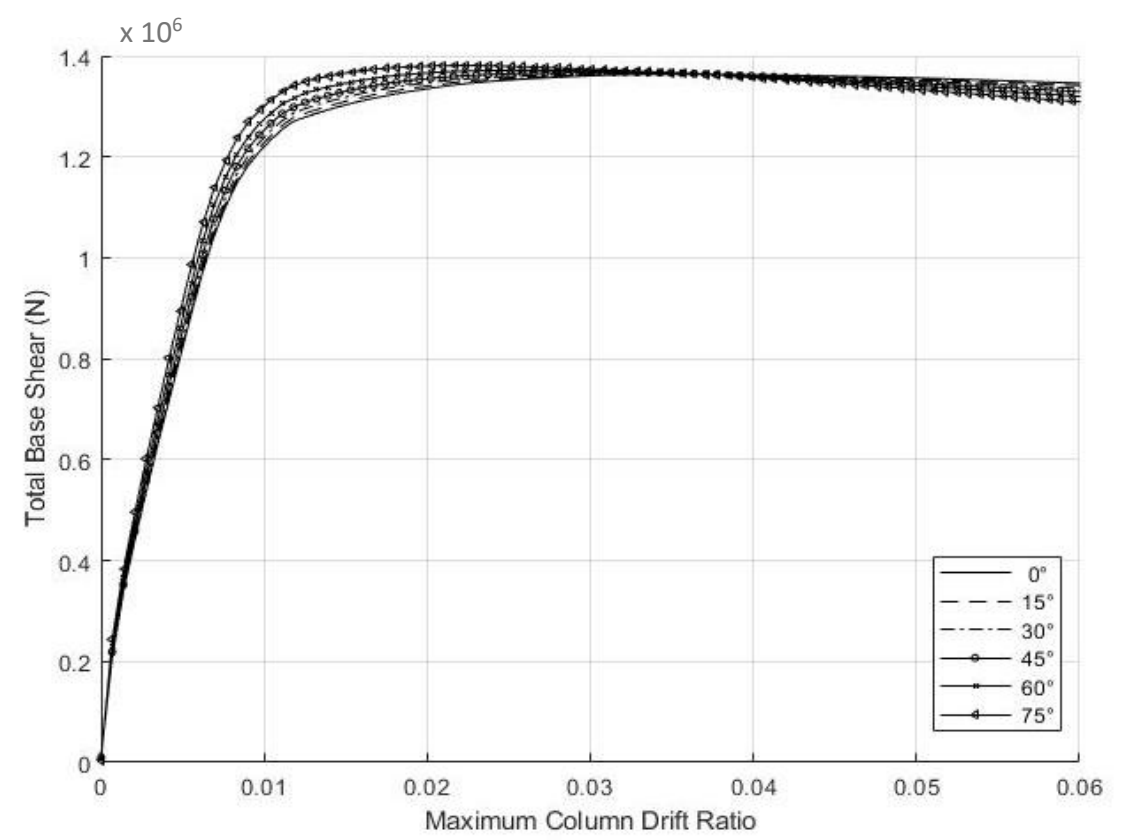

Figure 7 - total base shear force versus maximum column drift ratio from the pushover analysis

The studied analytical models have four columns, and a limit-state condition is assumed to be achieved when the CLD of any column reaches the specified drift criteria. Although the failure of one column may not necessarily correspond to the collapse of the structure as a whole, this more conservative definition of failure limit-state condition is used in the study. The limit-state function $\mathrm{g}(\mathrm{x})$ is defined as follows:

$$
\mathrm{g}(\mathrm{x})=\mathrm{CLD}_{\mathrm{LS}}-\max \left[\operatorname{CLD}_{\mathrm{C} 1}(\mathrm{x}), \operatorname{CLD}_{\mathrm{C} 2}(\mathrm{x}), \operatorname{CLD}_{\mathrm{C} 3}(\mathrm{x}), \operatorname{CLD}_{\mathrm{C} 4}(\mathrm{x})\right] \leq 0
$$

where $C_{L D}$ is the threshold CLD value of the limit state, and $\operatorname{CLD}_{\mathrm{C} 1}(\mathrm{x}), \mathrm{CLD}_{\mathrm{C} 2}(\mathrm{x}), \mathrm{CLD}_{\mathrm{C} 3}$ $(\mathrm{x})$, and $\mathrm{CLD}_{\mathrm{C} 4}(\mathrm{x})$ denote the CLDs of the four columns (C1-C4). In this equation, CLD $\mathrm{LS}$ represents the seismic capacity provided by a bridge, and the maximum CLD of columns represents the seismic demand imposed by the earthquake. Table 4 shows the threshold CLD ratio values of three limit states for all analytical models. It is noted that the threshold value decreases with the increase of skewness angle.

Table 4 - Column drift ratio (\%) values of limit states

\begin{tabular}{|c|c|c|c|c|c|c|}
\hline \multirow{2}{*}{ Limit state } & \multicolumn{6}{|c|}{ CLD ratio (\%) } \\
\cline { 2 - 7 } & SK000 & SK015 & SK030 & SK045 & SK060 & SK075 \\
\hline Serviceability & 0.570 & 0.569 & 0.567 & 0.563 & 0.555 & 0.541 \\
\hline Damage Control & 0.900 & 0.850 & 0.800 & 0.750 & 0.700 & 0.650 \\
\hline Collapse Prevention & 1.950 & 1.900 & 1.800 & 1.75 & 1.550 & 1.250 \\
\hline
\end{tabular}




\section{Seismic Vulnerability Curves.}

\subsection{Effects of Skewness angle on the seismic performance of bridges}

To explain the effect of skew angle on the seismic performance of bridges, a simplified set of pier columns is considered with different skewness angles ranging from $0^{\circ}$ to $90^{\circ}$ skew angle with incremental step $10^{\circ}$ as shown in Figure 8. The comparison between the Column drift (\%) for the models with different skewness angles with respect to the base shear is presented in Figure 9.

It can be concluded that the lateral stiffness of the system increased with the increase of the skewness angle, which explains the decrease in the fundamental periods of the bridges, as shown in Table 1. However, the deformation stiffness decreases as the skewness angle increases due to the torsional moment effect on the columns, increasing the bridge's fragility.

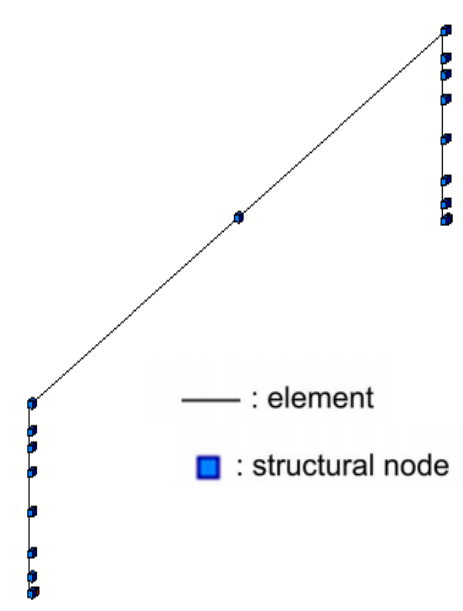

Figure 8 - Simplified set of piers columns model

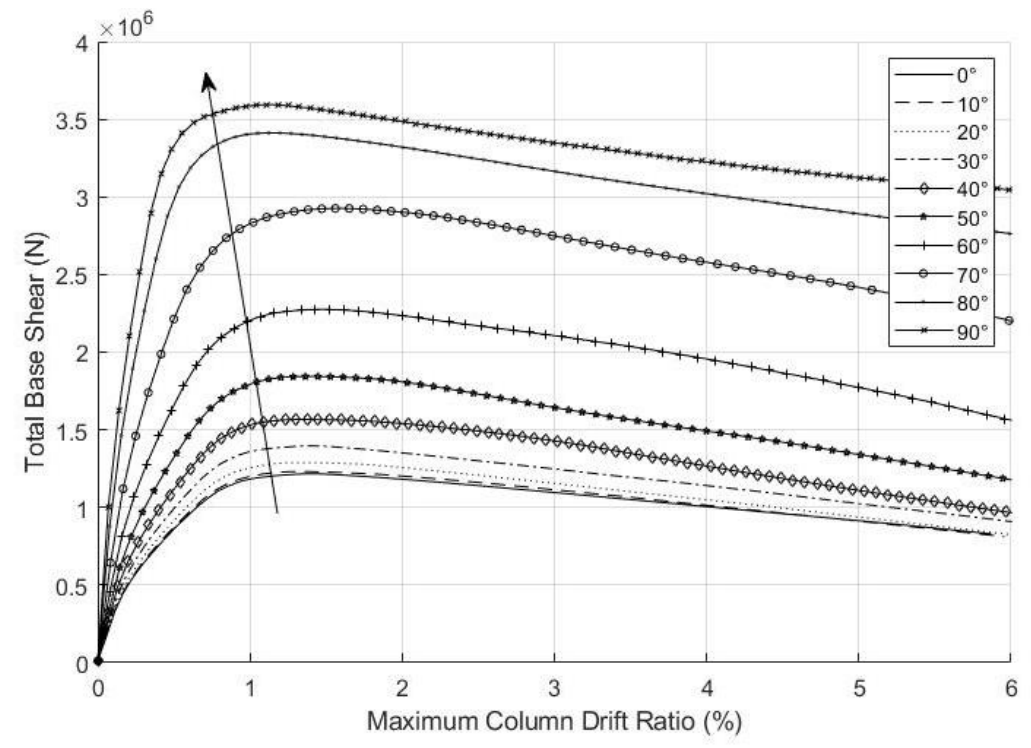

Figure 9 - Maximum column drift ratio (\%) with respect to the Total base shear

\subsection{Seismic fragility curves}

The integrated platform FERUM-ZEUS was used to drive the vulnerability curves for the threedimensional RC bridges with various skew angles from straight to highly skewed, as shown in Figure 10. In the figure, each graph has fragility curves for eight limit states. Each point is a failure probability calculated from a series of structural and reliability analyses. Note that material uncertainty is considered, and an analytical model in each simulation has different steel and concrete strength. The fitted log-normal curves are plotted. The fragility curve of the $0.25 \%$ limit-state is 
moved to the left of one of the $2.00 \%$ limit-state. It is noteworthy that seismic fragility curves are affected by the skewness angle.

(a)

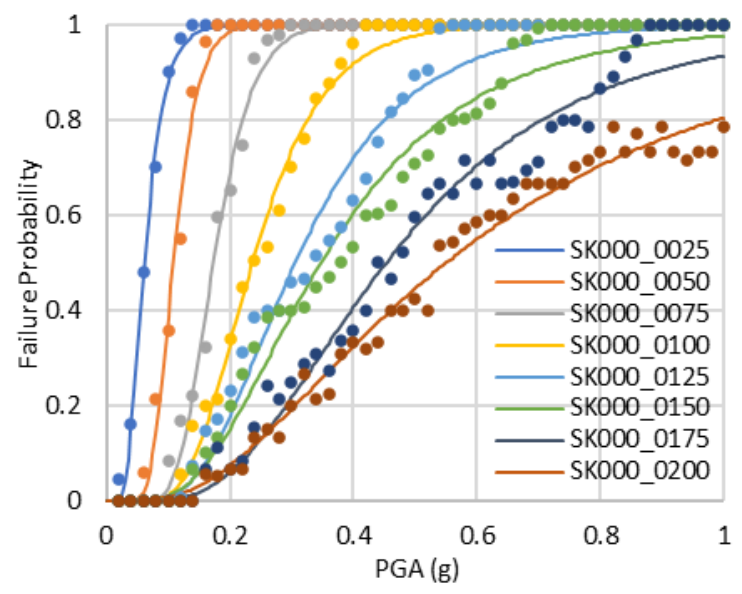

(c)

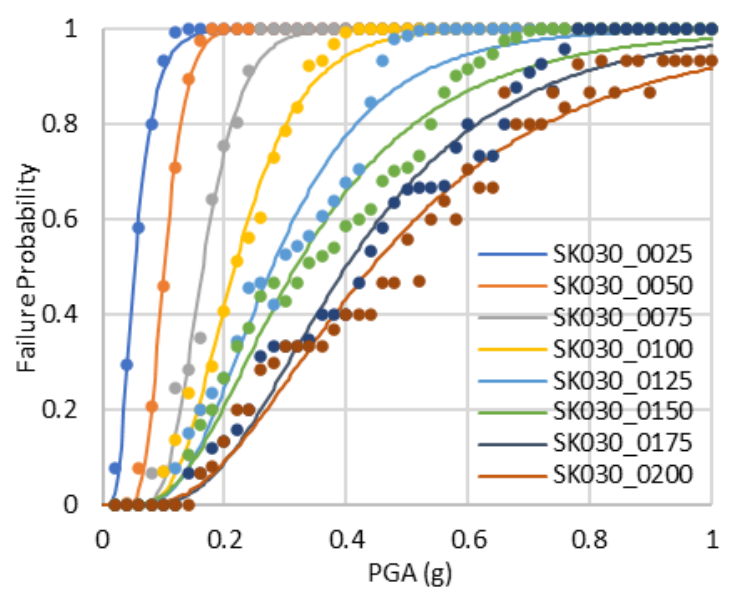

(e)

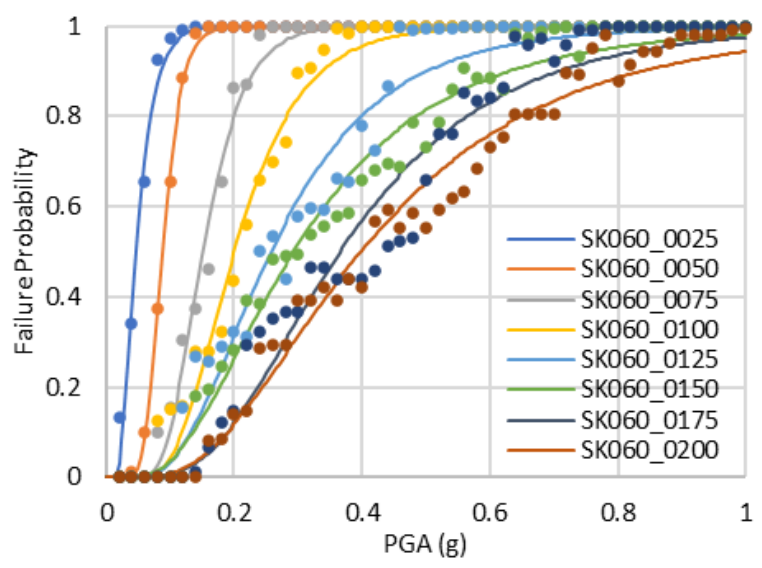

(b)

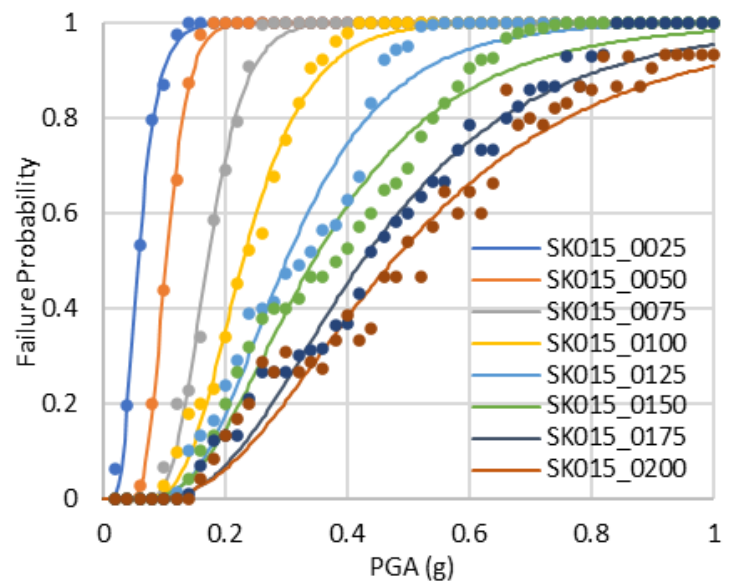

(d)

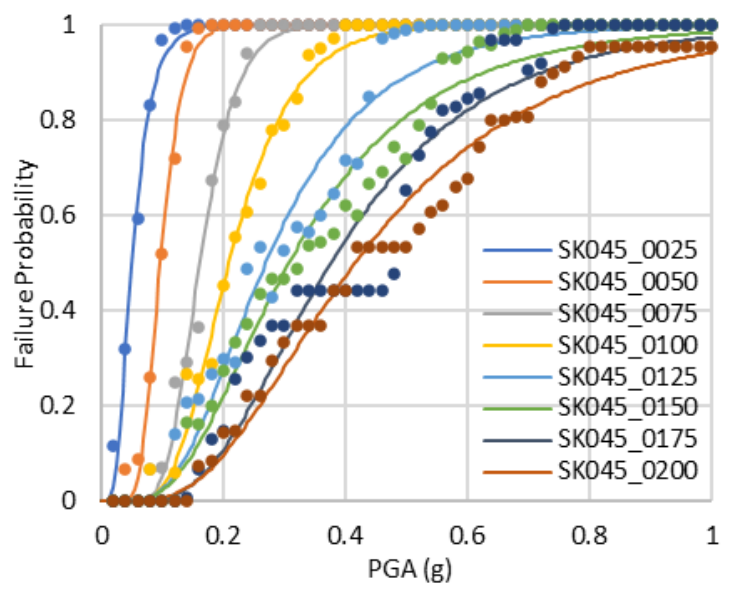

(f)

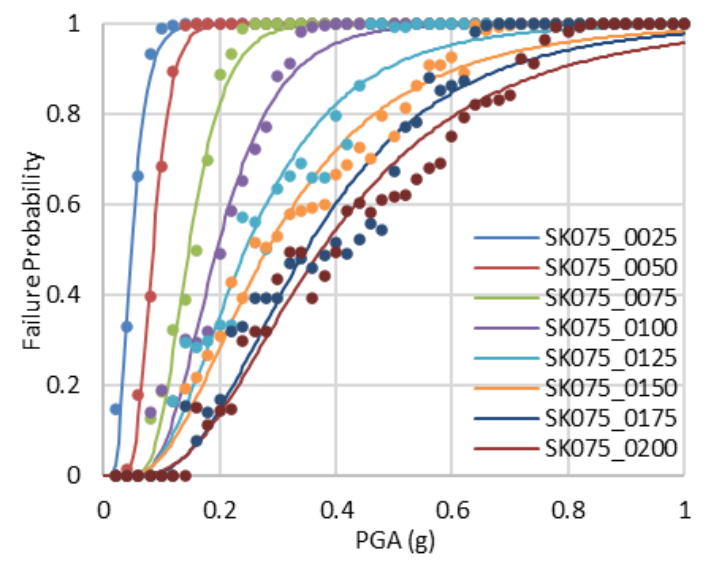

Figure 10 - Seismic fragility curves of bridges with different skew angles: (a) $0^{\circ}$ (SK000); (b) $15^{\circ}$

(SK015); (c) 30 (SK030); (d) 45 (SK045); (e) 60 (SK060); and (f) (c) $75^{\circ}$ (SK075). 
(a)

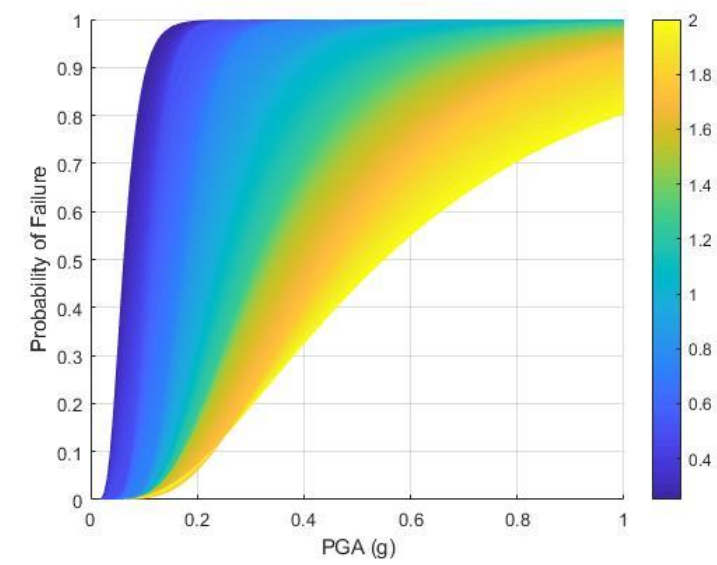

(c)

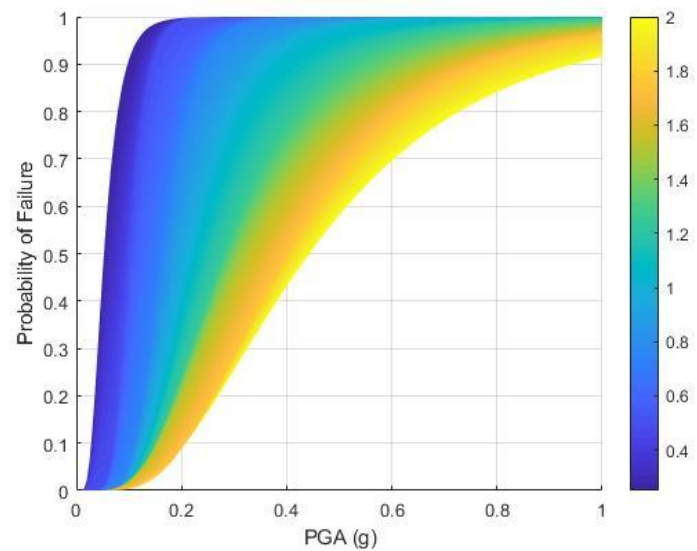

(e)

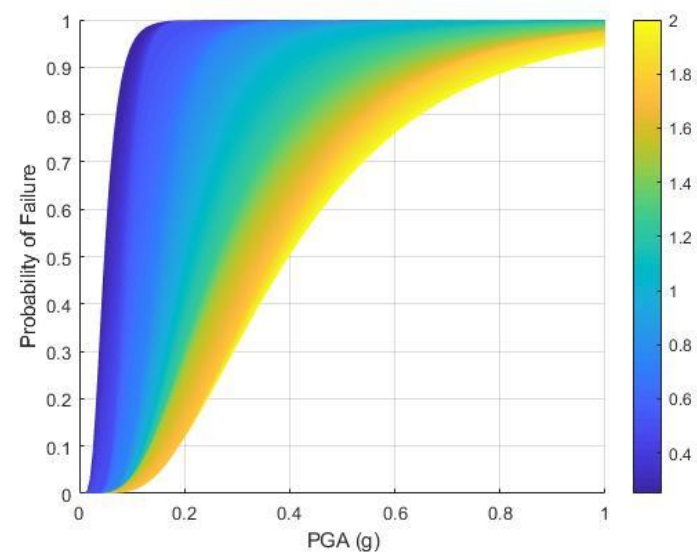

(b)

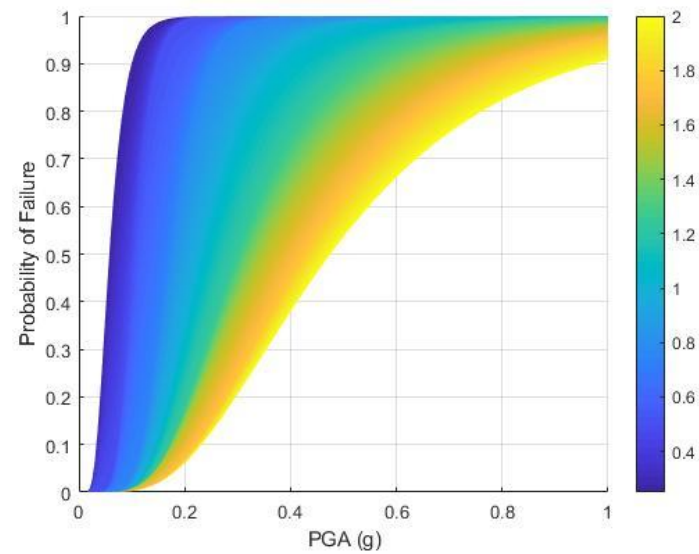

(d)

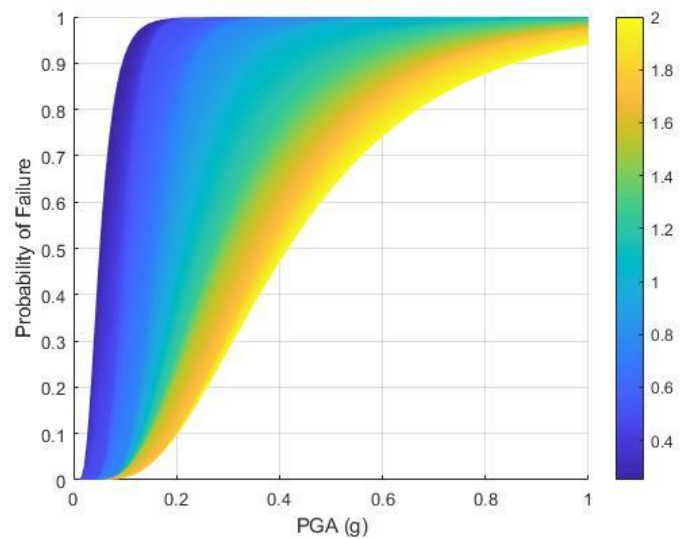

(f)

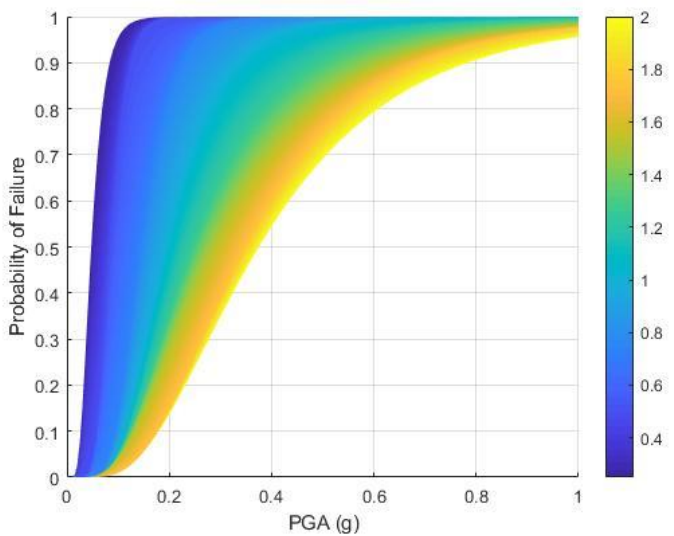

Figure 11- Seismic fragility curves of bridges with different skew angles: (a) $0^{\circ}$ (SK000); (b) $15^{\circ}$

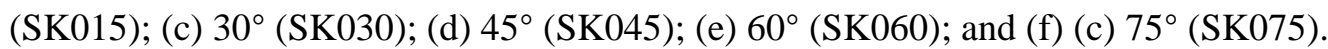


In this research, structural and reliability analyses were conducted for eight bridge models with different skewness angles with various limit states. In figure 11, each plot shows the fragility curves of one of the skewed bridge models with respect to different limit states. Also, we can estimate the probability of failure of the bridge affected by an earthquake given its peak ground acceleration and the desired limit state.

A series of regression analyses were performed to get a functional form for each fragility curve, and the log-normal cumulative distributions were used to represent the fragility curves. After fitting the data in a least-square sense, the mean and the variance was obtained. Table 5 tabulates log-normal means and variances for seismic fragility curves of all studied bridge models with different column drift ratios.

Table 5 - Log-normal parameters for seismic fragility curves of studied bridge models

\begin{tabular}{|c|c|c|c|c|c|c|c|}
\hline \multirow{2}{*}{\multicolumn{2}{|c|}{ Column Drift ratio (\%) }} & \multicolumn{6}{|c|}{ Models } \\
\hline & & \multirow{2}{*}{$\frac{\text { SK000 }}{0.07115}$} & \multirow{2}{*}{$\frac{\text { SK015 }}{0.06691}$} & \multirow{2}{*}{$\frac{\text { SK030 }}{0.06659}$} & \multirow{2}{*}{$\begin{array}{c}\text { SK045 } \\
0.06519\end{array}$} & \multirow{2}{*}{$\begin{array}{l}\text { SK060 } \\
0.0631\end{array}$} & \multirow{2}{*}{$\frac{\text { SK075 }}{0.06102}$} \\
\hline 025 & Mean & & & & & & \\
\hline $0.2 \mathrm{~J}$ & Variance & 0.00119 & 0.00106 & 0.00097 & 0.00084 & 0.0008 & 0.00079 \\
\hline \multirow{2}{*}{0.50} & Mean & 0.11691 & 0.11625 & 0.11328 & 0.11321 & 0.11245 & 0.11098 \\
\hline & Variance & 0.00143 & 0.00119 & 0.00114 & 0.00108 & 0.00103 & 0.00098 \\
\hline \multirow{2}{*}{0.75} & Mean & 0.1807 & 0.17786 & 0.17016 & 0.16901 & 0.16795 & 0.16683 \\
\hline & Variance & 0.00273 & 0.0026 & 0.00252 & 0.00233 & 0.00214 & 0.0021 \\
\hline \multirow{2}{*}{1.00} & Mean & 0.25386 & 0.24914 & 0.23127 & 0.22073 & 0.20185 & 0.19312 \\
\hline & Variance & 0.01029 & 0.00903 & 0.00849 & 0.00815 & 0.00796 & 0.00732 \\
\hline \multirow{2}{*}{1.25} & Mean & 0.34417 & 0.34312 & 0.33888 & 0.33371 & 0.33017 & 0.3299 \\
\hline & Variance & 0.02898 & 0.02659 & 0.02515 & 0.02412 & 0.0231 & 0.02283 \\
\hline \multirow{2}{*}{1.50} & Mean & 0.42894 & 0.42752 & 0.40544 & 0.4011 & 0.40041 & 0.39326 \\
\hline & Variance & 0.06739 & 0.05723 & 0.05335 & 0.05239 & 0.04934 & 0.04667 \\
\hline \multirow{2}{*}{1.75} & Mean & 0.52969 & 0.51184 & 0.50695 & 0.48934 & 0.48444 & 0.47574 \\
\hline & Variance & 0.12205 & 0.12167 & 0.10717 & 0.07773 & 0.07165 & 0.06958 \\
\hline \multirow{2}{*}{2.00} & Mean & 0.71218 & 0.65579 & 0.62446 & 0.60457 & 0.5702 & 0.55596 \\
\hline & Variance & 0.30162 & 0.21287 & 0.20819 & 0.18939 & 0.15468 & 0.11392 \\
\hline
\end{tabular}

In figure 12 shows the relation between peak ground acceleration (PGA) and failure probability of the eight studied skewed bridge models. Each plot compares the fitted log-normal curve of the different studied models at the same limit state, which varies from $0.25 \%$ to $2.00 \%$ with an increment of $0.25 \%$. Notably, the fragility curve shifts toward the left as the skew angle increases; in other words, the likelihood of failure increases with the increase of bridge irregularity. 
(a)

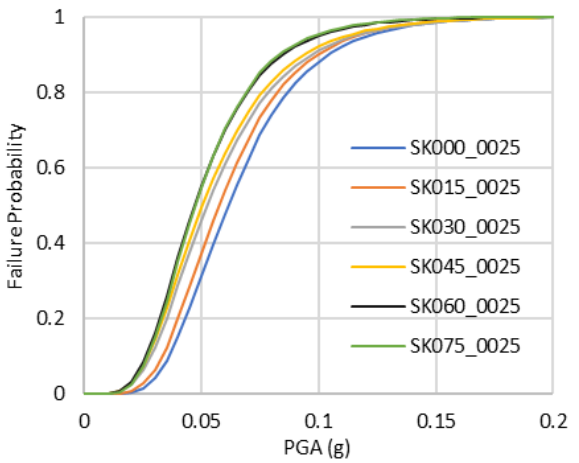

(c)

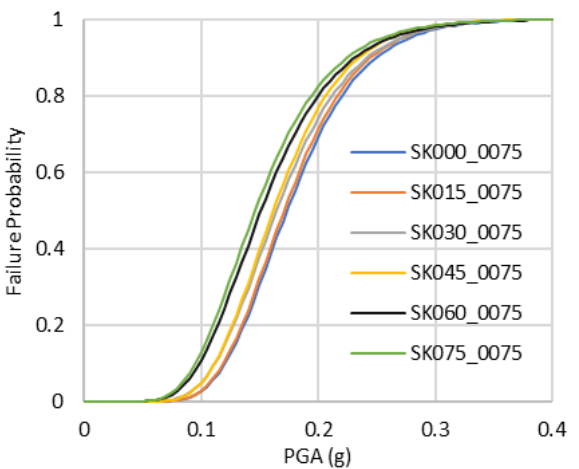

(e)

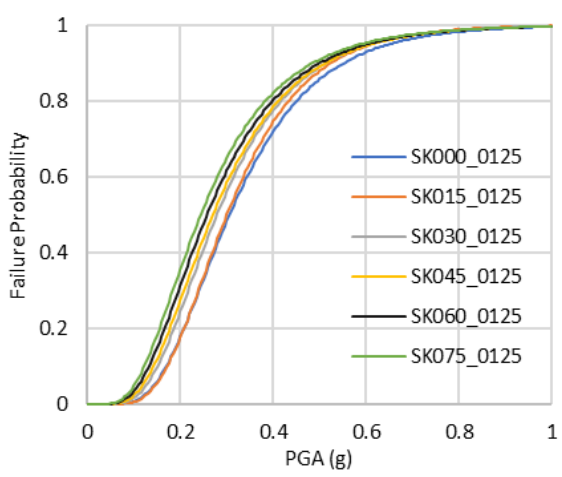

$(\mathrm{g})$

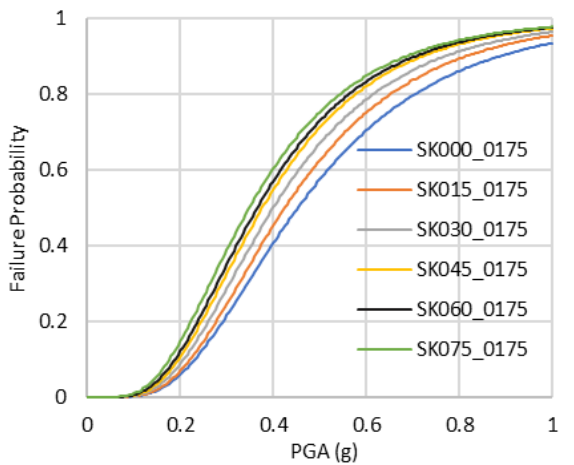

(b)

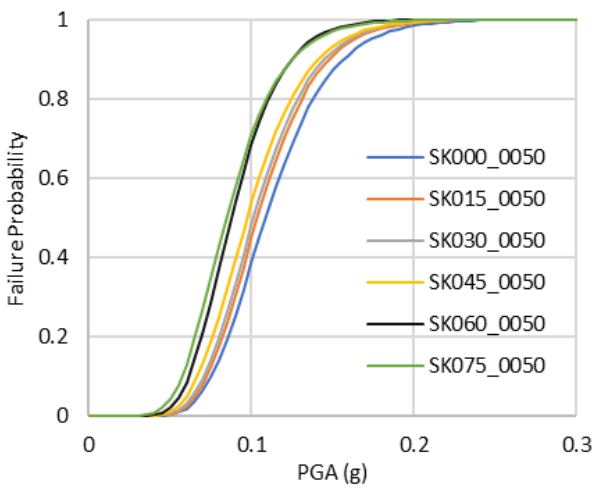

(d)

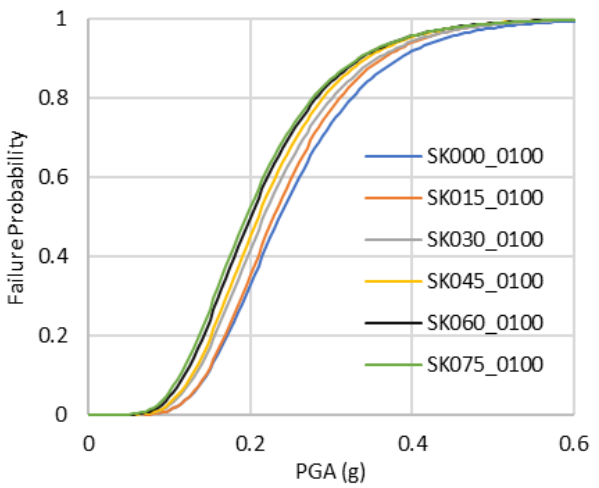

(f)

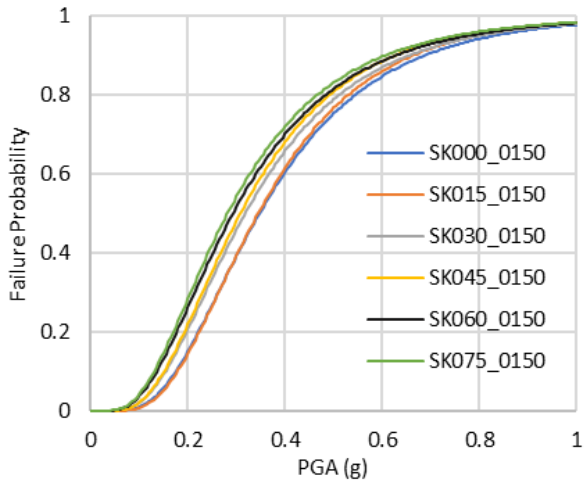

(h)

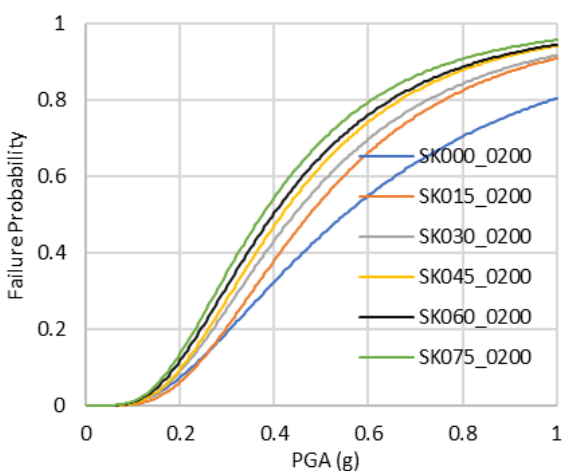

Figure 12 - Seismic fragility surfaces of bridges with different limit states: (a) $0.25 \%$; (b) $0.50 \%$; (c) $0.75 \%$ (d) $1.00 \%$; (e) $1.25 \%$; (f) $1.50 \%$; (g) $1.75 \%$; and (h) $2.00 \%$. 
The effect of bridge irregularity on seismic vulnerability is investigated by comparing fragility curves and their statistical parameters. Figures 13 and 14 show how the skewness angle affects the log-normal mean and variance value and depict fitted curves with linear, respectively. Table 6 shows the fitted curve equation and $\mathrm{R}^{2}$ for mean and variance at different column drift ratios, respectively. It is demonstrated that the three-dimensional skewed reinforced concrete bridges having high skewness angles are much more vulnerable than the regular bridges.

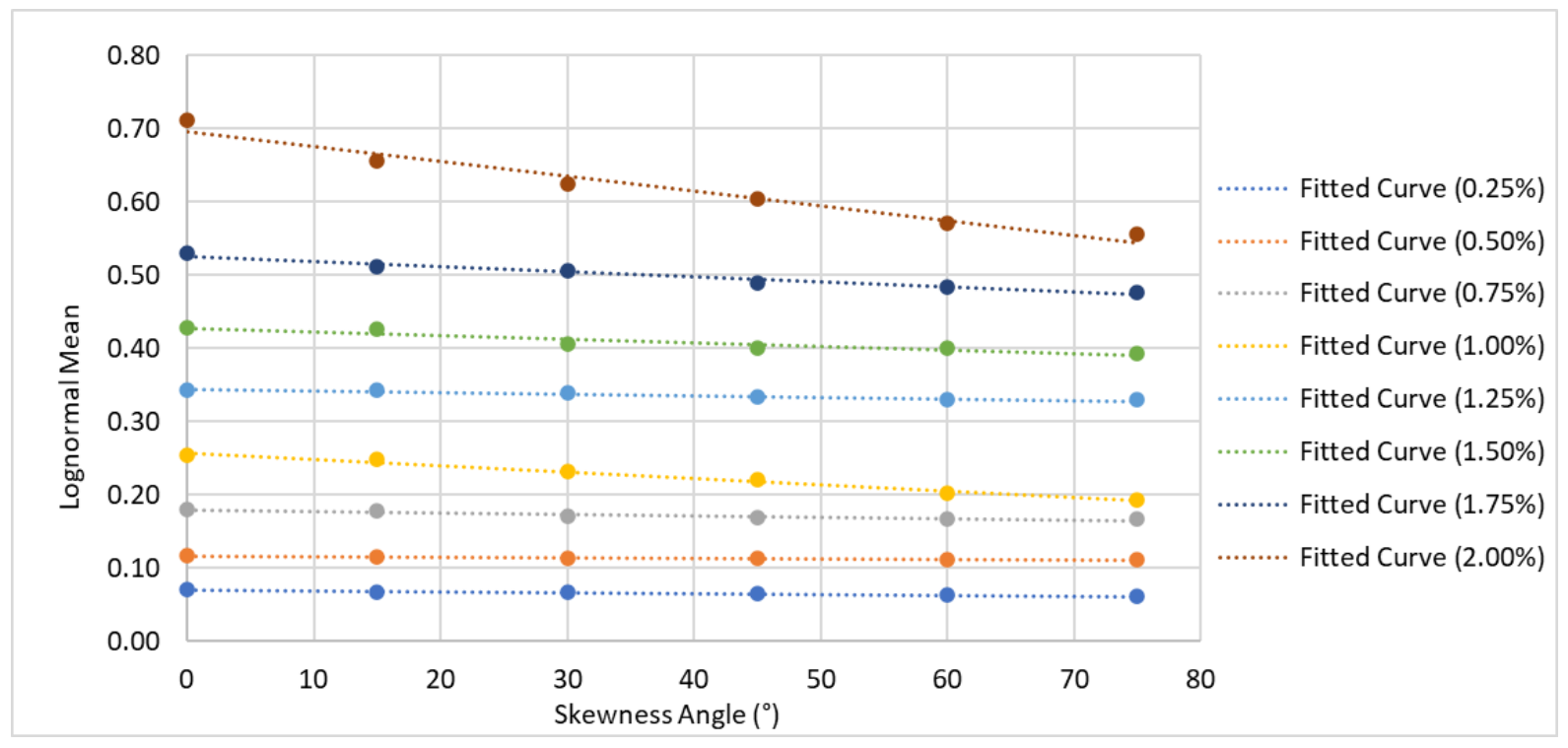

Figure 13 - Variation of log-normal mean with the bridge skew angles

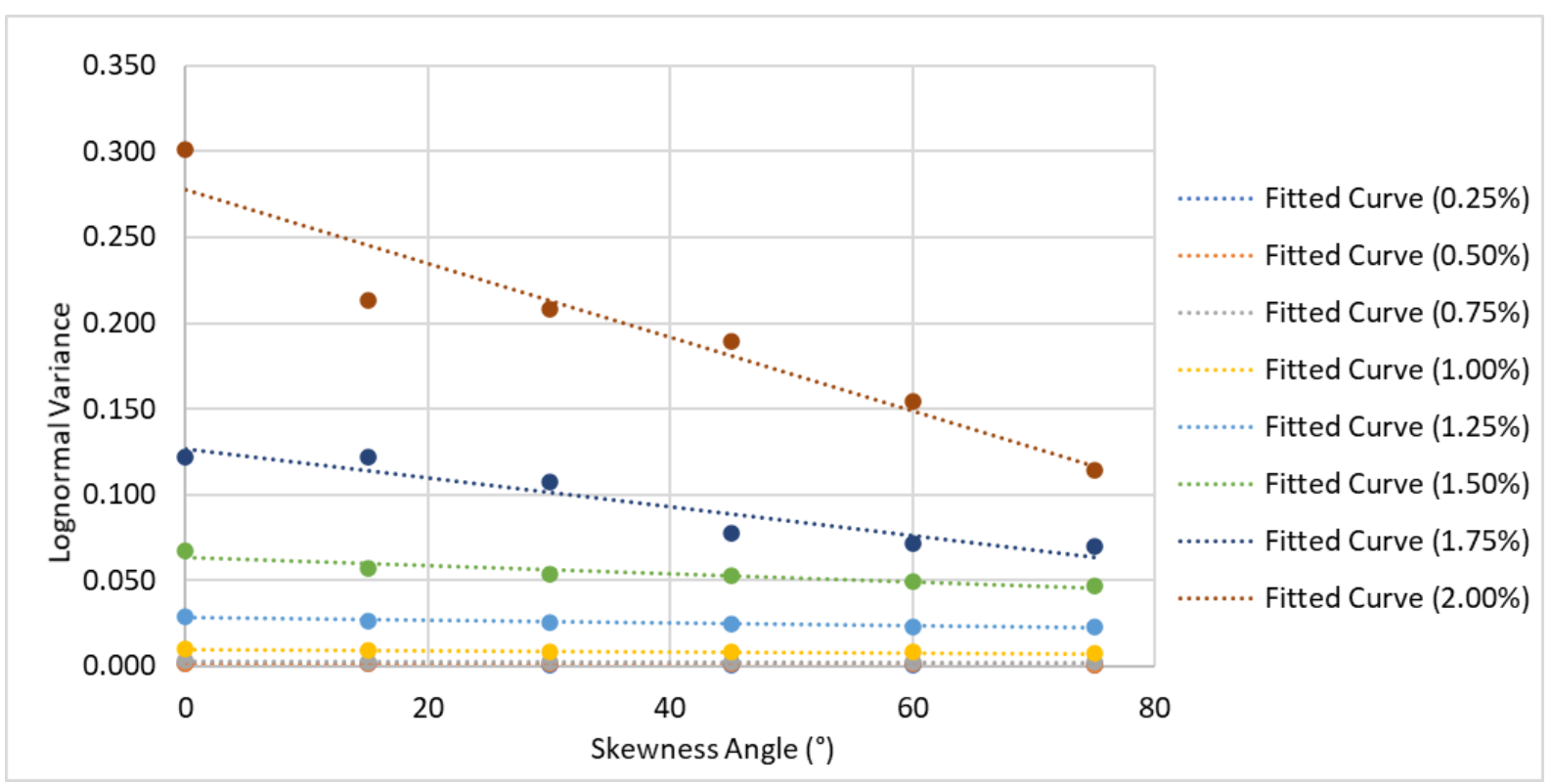

Figure 14 - Variation of log-normal variance with the bridge skew angles 
Table 6 - Fitted curve equation and $\mathrm{R}^{2}$ for mean and variance at different column drift ratios.

\begin{tabular}{|c|c|c|c|c|}
\hline \multirow{2}{*}{$\begin{array}{c}\text { Column Drift } \\
\text { Ratio (\%) }\end{array}$} & \multicolumn{2}{|l|}{ Mean } & \multicolumn{2}{|l|}{ Variance } \\
\hline & Equation & $\mathrm{R}^{2}$ & Equation & $\mathrm{R}^{2}$ \\
\hline 0.25 & $y=-0.0001 x+0.0702$ & 0.9457 & $y=-6 E-06 x+0.0011$ & 0.9314 \\
\hline 0.50 & $y=-8 E-05 x+0.1168$ & 0.9271 & $y=-5 E-06 x+0.0013$ & 0.8696 \\
\hline 0.75 & $y=-0.0002 x+0.1792$ & 0.8675 & $y=-9 E-06 x+0.0027$ & 0.9771 \\
\hline 1.00 & $y=-0.0009 x+0.2576$ & 0.9823 & $y=-4 E-05 x+0.0099$ & 0.9157 \\
\hline 1.25 & $y=-0.0002 x+0.3449$ & 0.9527 & $y=-8 E-05 x+0.0281$ & 0.9312 \\
\hline 1.50 & $y=-0.0005 x+0.4283$ & 0.8769 & $y=-0.0002 x+0.0636$ & 0.8790 \\
\hline 1.75 & $y=-0.0007 x+0.5261$ & 0.9689 & $y=-0.0008 x+0.1265$ & 0.9053 \\
\hline 2.00 & $y=-0.0020 x+0.6961$ & 0.9620 & $y=-0.0022 x+0.2776$ & 0.9118 \\
\hline
\end{tabular}

Figure 15 compares fragility curves for different bridge models with the given three limit states. The fragility curve shifts toward the left as the skew angle increases; in other words, the likelihood of failure increases with bridge irregularity. As seen in the figure, the skewness angle significantly impacts bridge performance during earthquakes or seismic vulnerability. This agrees well with the fact that skewed bridges are highly vulnerable to earthquake damage, as evidenced by bridge damages and losses to such bridges during past earthquakes.

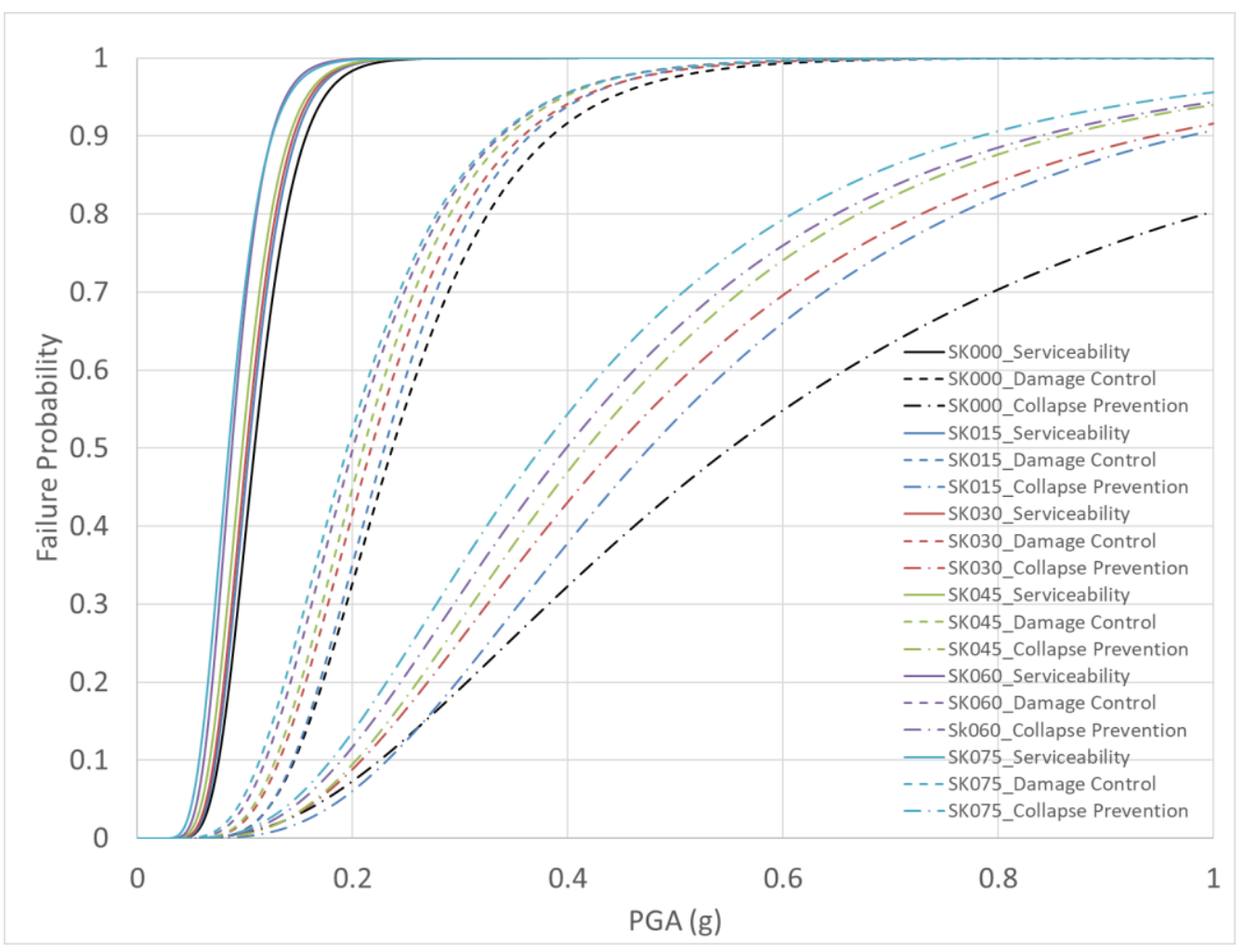

Figure 15 - Effect of bridge skew angles on seismic fragility curves 
(a)

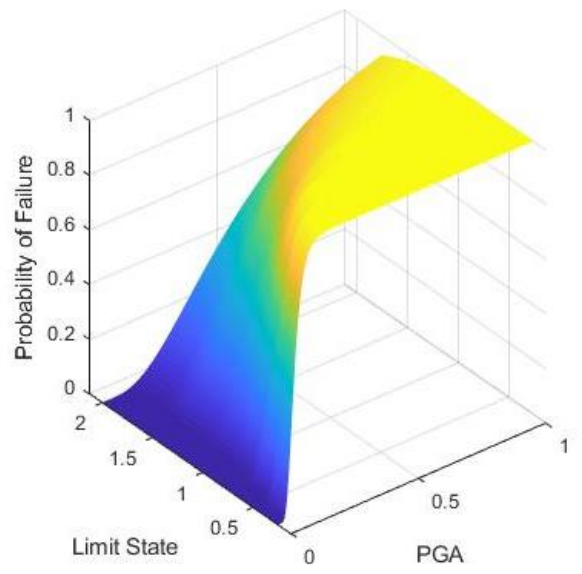

(c)

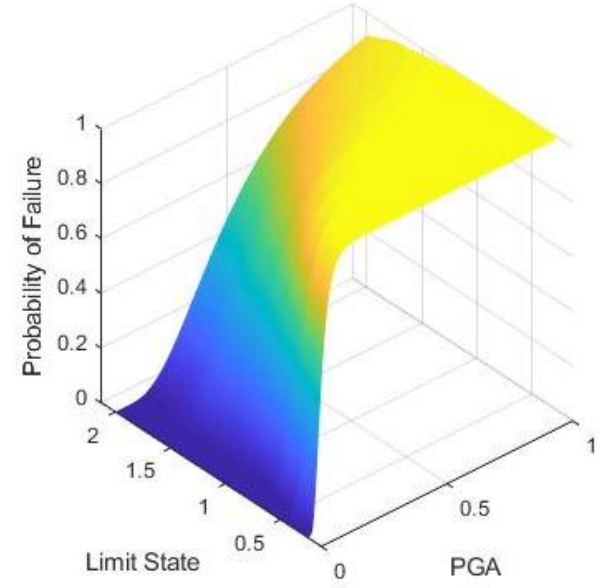

(e)

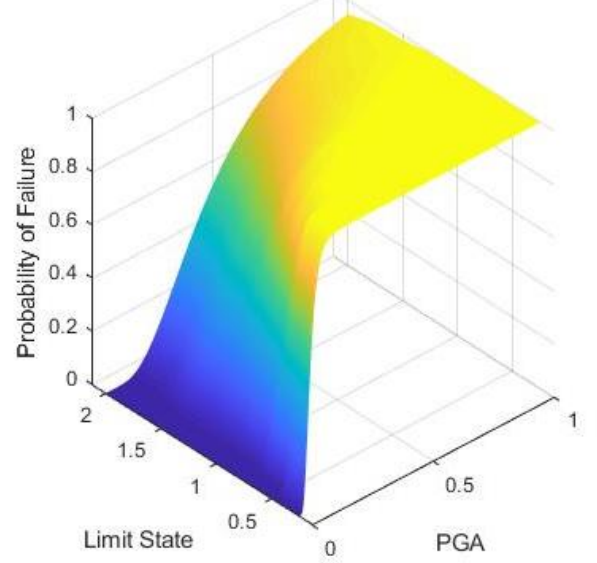

(b)

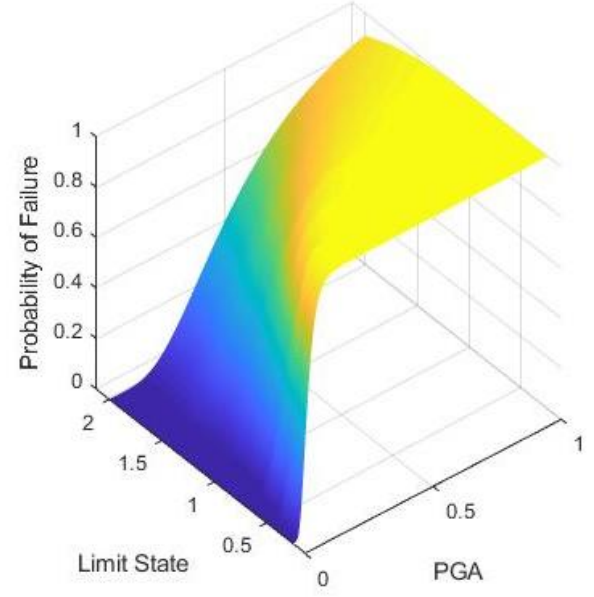

(d)

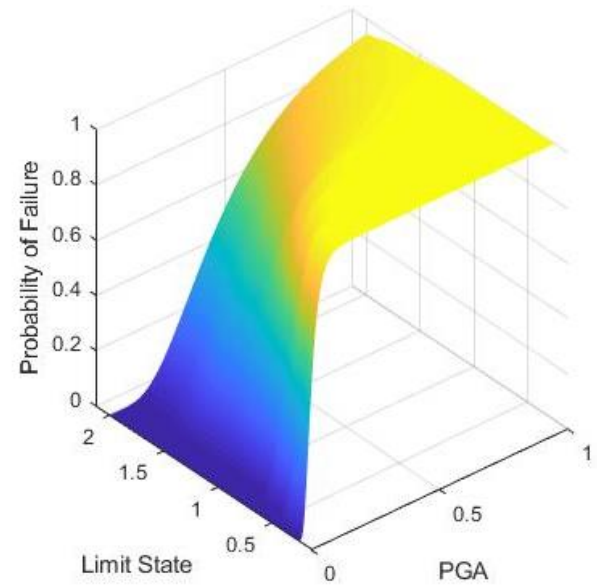

(f)

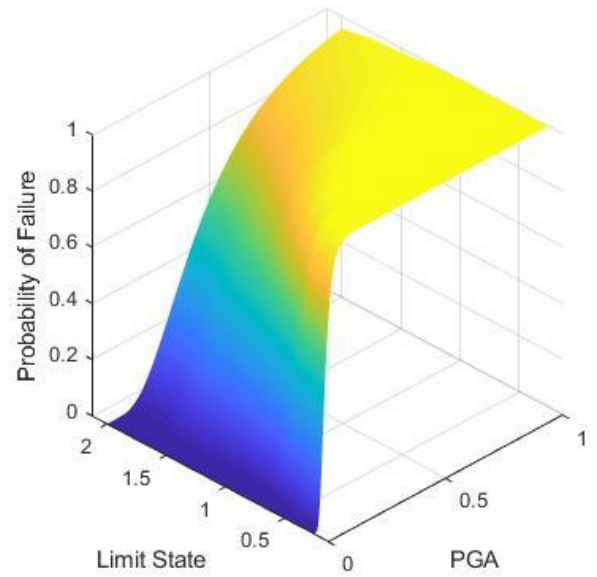

Figure 16 - Seismic fragility surface of bridges with different skew angles: (a) $0^{\circ}$ (SK000); (b) $15^{\circ}$ (SK015); (c) 30 (SK030); (d) 45 (SK045); (e) 60 (SK060); and (f) (c) $75^{\circ}$ (SK075). 
Figure 16 plots seismic fragility surfaces of three-dimensional skewed reinforced concrete bridges. In this figure, each graph has a fragility surface for various limit states. As shown, different ground motions and bridge skew angles produce significant differences in seismic fragility curves. As expected, the failure probability increases with a stricter definition of the damage state. If the same 3D numerical analysis were performed by Monte Carlo simulation to get the fragility curve, it would be extremely computationally expensive, especially with three-dimensional models.

\section{Summary and Conclusion}

This research focuses on the effect of skew angle and aims to derive a more accurate seismic vulnerability analysis of three-dimensional skewed reinforced concrete (RC) bridges. Different bridge models, from the straight to highly skewed, are analyzed. Compared to simplified models, threedimensional bridge models were used to accurately estimate highly non-linear structural behavior due to the torsional moment effect on the columns. To overcome the challenge in using computationally demanding models in deriving fragility curves, a new method was introduced to calculate the failure probability efficiently and accurately using the integrated platform FERUM-ZEUS, which was used as a linking interface between FERUM for reliability analysis and ZEUS-NL for structural analysis. Also, the FORM was used as an estimation tool to evaluate the failure probabilities.

Six different bridge models were developed, with a different skewed angle from 0 to 75 -degree skewed angle with an increment of 15-degree. A selected set of 15 earthquake ground motions were used to impose consistent seismic demands on structures. Uncertainty in both the structural capacity and the earthquake demand was considered. Pushover analysis was used to determine the limit states, serviceability, and damage control.

The results of the seismic fragility curves clearly show that the skewed reinforced concrete bridges become much vulnerable to earthquake damage as the skewness angle increases. This matches with the previous research results and the actual damage observed in past earthquakes. Bridge irregularity is one of the major causes of the failure or collapse of bridges, so considerable attention should be paid when conducting seismic vulnerability analysis. This study provides seismic fragility surfaces for RC bridge models with varying column skewed angles, but in general, the application may be limited because seismic performance could be very different depending on the bridge's configuration and the damage state definition. 


\section{References}

[1] Fung G.G., LeBeau R.J., Klein E.E., Belvedere J., and Goldschmidt A.F. (1971): Field investigation of bridge damage in the San Fernando earthquake. State of California, Division of Highways, Bridge Department.

[2] Buckle I.G. (1994): Performance of Highway Bridges. Technical Report NCEER-94-0008, National Center for Earthquake Engineering Research, University at Buffalo.

[3] Anderson D.L., Mitchell D. and Tinawi R.G. (1995): Performance of concrete bridges during the HyogoKen Nanbu(Kobe) earthquake. Canadian Journal of Civil Engineering.

[4] Yashinsky M, (2010): Performance of highway and railway structures during the February 27, 2010, Maule Chile earthquake. EERI/PEER/FHWA Bridge Team Report.

[5] Unmukt R. Bhatnagar \& Swagata Banerjee (2015): Fragility of skewed bridges under orthogonal seismic ground motions. Structure and Infrastructure Engineering.

[6] Kim, S. H., \& Feng, M. Q. (2003): Fragility analysis of bridges under ground motion with spatial variation. International Journal of Non-Linear Mechanics.

[7] Zakeri, B., Padgett, J. E., \& Ghodrati Amiri, G. (2015): Fragility assessment for seismically retrofitted skewed reinforced concrete box girder bridges. Journal of Performance of Constructed Facilities.

[8] Bhatnagar UR, Banerjee S (2015) Fragility of skewed bridges under orthogonal seismic ground motions. Struct Infrastruct Eng 11(9):1113-1130

[9] Soltanieh S, Memarpour MM, Kilanehei F (2019) Performance assessment of bridge-soil-foundation system with irregular configuration considering ground motion directionality effects. Soil Dyn Earthq Eng 118:19-34

[10] Wei B, Zuo C, He X et al. (2018) Effects of vertical ground motions on seismic vulnerabilities of a continuous track-bridge system of high-speed railway. Soil Dyn Earthq Eng 115:281-290

[11] Jeon J, Shafeezadeh A, Lee DH, et al. (2015) Damage assessment of older highway bridges subjected to three-dimensional ground motions: characterization of shear-axial force interaction on seismic fragilities. Eng Struct 87:47-57

[12]Zakeri B, Padgett JE, Ghodrati Amiri G. Fragility assessment for seismically retrofitted skewed reinforced concrete box girder bridges. J Perform Constr Facil 2015. 
[13]FHWA (1996): Seismic Design of Bridges - Design Example No.4. Office of Engineering and Highway Operations R\&D, Federal Highway Administration.

[14] Lee, Y.-J., and D.-S. Moon. 2014. "A new methodology of the development of seismic fragility curves." Smart Struct. Syst. 14 (5): 847-867.

[15] Jeong, S. H., \& Elnashai, A. S. (2007): Probabilistic fragility analysis parameterized by fundamental response quantities. Engineering Structures.

[16] Rossetto, T., \& Elnashai, A. (2003): Derivation of vulnerability functions for European-type RC structures based on observational data. Engineering structures.

[17] Kwon, O. S., \& Elnashai, A. S. (2007): Fragility analysis of a bridge with consideration of soil-structureinteraction using multi-platform analysis. In Structural Engineering Research Frontiers (pp. 1-14).

[18] Melchers RE (1999): Structural reliability: analysis and prediction. 2nd Edition, John Wiley, New York, NY.

[19] Moon, D. S., Lee, Y. J., \& Lee, S. (2018): Fragility analysis of space reinforced concrete frame structures with structural irregularity in plan. Journal of Structural Engineering, 144(8), 04018096.

[20]Zhang Y. and Der Kiureghian A. (1995): Two improved algorithms for reliability analysis. In Reliability and Optimization of Structural Systems.

[21]Lee, Y. J., \& Moon, D. S. (2014): A new methodology of the development of seismic fragility curves. Smart Structures and Systems, 14(5), 847-867.

[22] Haukaas, T., \& Der Kiureghian, A. (2005): Parameter sensitivity and importance measures in non-linear finite element reliability analysis. Journal of engineering mechanics, 131(10), 1013-1026.

[23] Kwon, O. S., \& Elnashai, A. S. (2010): Fragility analysis of a highway over-crossing bridge with consideration of soil-structure interactions. Structure and Infrastructure Engineering, 6(1-2), 159-178.

[24] Jeong, H. I., Sakai, J., and Mahin, S. A. (2008): Shaking table tests and numerical investigation of selfcentering reinforced concrete bridge columns. Pacific Earthquake Engineering Research Center, Berkeley, CA.

[25] Martínez-Rueda, J. E., and A. Elnashai. 1997. Confined concrete model under cyclic load. Mater. Struct. 30 (3): 139-147. 
[26] Pavel, F., and Lungu, D. (2013). Correlations between frequency content indicators of strong ground motions and PGV. Journal of Earthquake Engineering, 17(4), 543-559.

[27] Bartlett, F. M., and J. G. Macgregor. (1996). Statistical analysis of the compressive strength of concrete in structures. ACI Mater. J. 93 (2): 158-168.

[28] Mirza, S. A., and J. G. MacGregor. (1979). Variability of mechanical properties of reinforcing bars. $J$. Struct. Div. 105 (5): 921-937.

[29] Ghanem, A. M., and Moon, D. S. (2021). Seismic Fragility Assessment of Skewed Reinforced Concrete Bridges. 17th World Conference on Earthquake Engineering (17WCEE), Sendai, Japan - September 2021. 